\title{
Remembering Klaus Peters
}

\section{Sigurdur Helgason and Dana Scott, Alice Peters and David Mumford}

\section{Sigurdur Helgason and Dana Scott}

Klaus Peters as Mathematical Publisher

This piece is a supplement to a biographical note in the December 2014 issue of the Notices dealing with the highly respected publisher of scientific books, Dr. Klaus Peters. Here we intend to describe in more detail his remarkable career as a publisher of mathematical books.

After his doctorate in complex analysis in 1962 from the University of Erlangen, Klaus served as assistant professor at Erlangen for two years. Then he was invited by Springer Verlag to be its first in-house mathematics editor. That same year Springer opened its American office in New York. In 1972 Klaus was named one of Springer's directors, and he hired Alice Merker, who had earned degrees from Rochester and Chicago, to be a mathematics editor at Springer New York. They married that year, settled in Heidelberg, and worked there at Springer Verlag. This account is based on Alice Peters's recollection of their publishing activity during the last forty years.

The 1970s were a boom time for Springer. In addition to several new major volumes, Klaus started at that time at least two new book series with American editors: Applied Mathematical Sciences and Undergraduate Texts in Mathematics (edited by Halmos). At the same time Alice started a computer science program at Springer. This included textbooks, monographs, and the various Lecture Notes Series.

Klaus felt from the start that in order to build an enlarged mathematics publishing program he would need a full commitment where he would have responsibility for all aspects of the publishing process: acquisition, editing, production, pricing, promotion, etc. He realized that in order

Sigurdur Helgason is professor of mathematics at the Massachusetts Institute of Technology. His email address is he1gason@mit. edu.

Dana Scott is Hillman University Professor of Computer Science, Philosophy, and Mathematical Logic, emeritus, at Carnegie Mellon University. His email address is dana. scott@cs.cmu . edu.

DOI: http://dx.doi.org/10.1090/noti1222 to build a world-class program, he would have to internationalize and involve American mathematicians. Richard Courant, who had maintained close ties with Springer even through the war, was his initial contact. They immediately forged a great relationship, and Courant introduced Klaus to the whole New York University/New Rochelle group, including Jürgen Moser, Fritz John, Kurt Friedrichs, Peter Lax, Cathleen Morawetz, among others, all of whom became trusted authors and advisors and also close personal friends. He also had close contact with Peter Hilton and Paul Halmos, both already editors of Ergebnisse der Mathematik. The connection with both Peter and Paul went beyond a professional relation, and Klaus considered both among his real friends.

\section{Lecture Notes in Mathematics}

Klaus was strongly involved with the beginning of Lecture Notes.
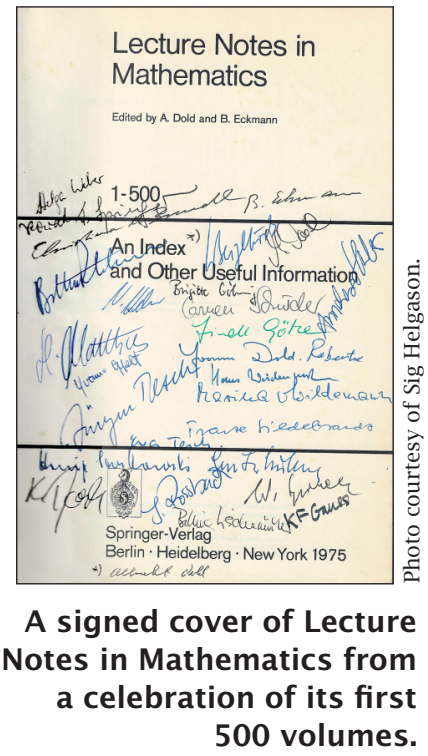

This may have come out of a discussion with Beno Eckmann (ETH Zurich) to find a way to distribute preprints or private communications that usually were sent only to a handful of closer colleagues to a wider audience, in particular, students. Klaus was convinced that this would be considered positively in the mathematics community and 
that it was timeliness rather than typesetting that would be the hallmark of the series. At the time, no one expected that the series would become so successful and respected. It now constitutes over two thousand volumes.

\section{The Mathematical Intelligencer}

The Mathematical Intelligencer was started by Alice, Klaus, and Walter Kaufmann-Buehler, their colleague in the mathematics editorial department at Springer. Walter had been working with Klaus, doing promotion for the math program, and he switched positions with Alice, taking her job at Springer NY after Klaus and Alice had met and decided to marry. The story of how and why the Intelligencer started is documented in an anniversary volume of the Intelligencer, Vol . 30 No. 1, 2008: pages 7-18 contain an interview with the founders.

In spite of successful publication activity, Klaus felt that financial considerations were gradually beginning to outweigh editorial decisions at Springer and thus would not preserve his ideal that the purpose of the company should be to do service to science. He failed to reach a satisfactory agreement with Springer owners on this issue and respectfully submitted his resignation.

\section{From Springer to Birkhäuser to $\mathrm{HBJ}$ to A K Peters}

In accordance with Klaus's point of view, Klaus and Alice decided to strike out on their own, intending to realize what he saw as a mathematical publisher's primary goal: service to the mathematical public. In his article [1] he outlines his philosophy of mathematical publishing, stressing particularly a publisher's obligation to the author to maximize the book's usefulness to the mathematical community. Most mathematicians know publishers for whom this obligation is secondary, even absent. A book, completely author prepared, may routinely be put out by a publisher as an eBook or printed only on demand, with a price of US\$100.

Following his vision, Klaus contacted Chari Einsele, owner and publisher of Birkhäuser, after which Einsele immediately suggested that Klaus and Alice move to Basel and "take charge" of Birkhäuser. Klaus did not see this as a viable situation, because he felt that a modern-day scientific publisher needed to have an American office and program. So Klaus and Alice moved to Boston and started Birkhäuser Boston in 1979.

This was a courageous move: settling in a new country with three children under four and, with no prior experience, starting and running a company. Alice was the principal computer expert in the group and became mainly involved on the financial and

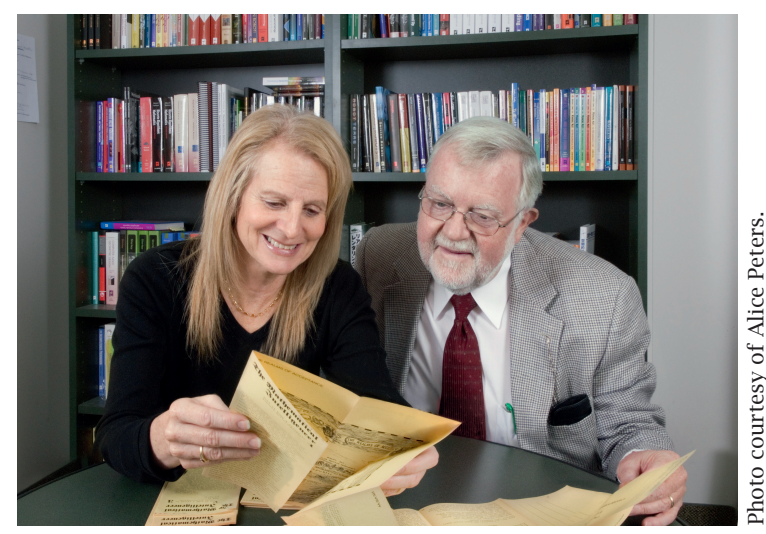

Alice and Klaus Peters.

production side. Klaus concentrated on the editorial work, starting the series Progress in Mathematics, which has now over one hundred fifty volumes. Birkhäuser grew and was thriving but then was put in jeopardy when the Birkhäuser printing company, owned also by the family, ran into difficulties. Through his contacts, Klaus arranged a sale of the publishing company to Harcourt Brace Jovanovich (Academic Press); however, this agreement fell apart because of a last-minute surprise takeover by Springer. Klaus then preferred to do something independent at that time, and, in fact, William Jovanovich quickly approached Klaus and Alice and asked them to start a new office for Harcourt Brace Jovanovich(HBJ)/Academic Press in Cambridge.

The Peters then built and managed the Boston office of HBJ, running Academic Press, and started the series Perspectives in Mathematics, which eventually included eighteen valuable books. They were responsible for the publishing program in mathematics, computer science, chemistry, and physics, with several other editors for the other fields. Unfortunately, HBJ ran into financial difficulties and was bought by General Cinema Corporation, which had little interest in the "idealistic" program envisioned by Klaus.

Klaus, with his passion and idealism, convinced Alice that they should start their own publishing company! With the help of Elwyn Berlekamp they then started A K Peters. The early years were hard for them and the company, both because of the long hours and financially. However, they held to their principles of publishing only high-quality books, even those whose sales would possibly be limited, as long as the books were of importance to the scientific community. Alice went to Babson College at night to complete work for her MBA in order to have a better knowledge of how to operate a business.

As the company grew, Klaus's interests also grew to include publishing in less-traditional 
areas for a high-level scientific publisher. A new journal, Experimental Mathematics, was launched with the help of David Epstein and Silvio Levy and published by A K Peters. It was devoted to experimental aspects of mathematical research, including mathematical influence (even proofs) by computer. This grew out of discussions Klaus and Alice had with David Mumford. Among the notable books they published were Hilbert and Courant, both by Constance Reid, The Honors Class by Benjamin Yandell, The Mathematical Experience by Philip Davis and Reuben Hersh, You Can Count on Monsters by Richard Evan Schwartz, and $A$ Cultural History of Physics by Károly Simonyi, as well as the popular book Mathematical People by Donald Albers and Gerald Alexanderson.

Klaus was extremely concerned about the state of education and sought ways to make mathematics more appealing. He saw the possibility to make a contribution by publishing stimulating books for young adults: a (fictionalized) biography of Gauss, a book on cryptography (Cryptoclub), and a whole program in recreational math, including origami, which he eventually worked on with the AMS. This really became a passion for him in later years.

He also made Herculean efforts to find ways to publish books that he felt should be made available, sometimes through clever sales of the books or through funding if the book could not support itself. With the last book that they published, Simonyi's The Cultural History of Physics, A K Peters sailed forth in full publishing glory. The book embodies Klaus's vision of the publication of a moderately priced masterpiece of very general interest, which in this case can be considered a work of art. Amazon.com contains some glowing endorsements. Sheldon Glashow's comments call it "fascinating for its wealth of data and for its anecdotal digressions," "marvelously filled with interesting and unfamiliar historical and technical explanations." In fact, Glashow, with Klaus's editorial help, was in the process of writing a supplementary volume.

A K Peters became what Klaus had envisioned: a company whose aim was to serve the scientific community. For over forty years, Alice and Klaus made a significant mark on mathematical publishing throughout the world. In the process, they published over one thousand books and earned universal goodwill in the mathematics community.

\section{References}

[1] KLAUS PETERS, Why publish mathematics? Notices of the AMS, August 1999.

[2] W. Kaufmann-BüHler, K. Peters, and A. Peters, Mathematicians love books, Mathematics Tomorrow, Springer, 1981, pp. 121-126.

\section{Alice Peters and David Mumford}

\section{Klaus Peters, Springer, and the Mission of Math Publishers}

Klaus was a man with strong ideals who loved publishing and poured his heart into his work. His life and many contributions to publishing have been detailed in the previous article. Here we want to focus on a battle that he waged, one that concerns the math community as a whole. He fought fiercely for the ideal of publishing in service to the professional community and believed that this required full editorial independence. He was not afraid to put his career on the line for these ideals, and this led to his resignation from Springer after he had nearly single-handedly brought them to the forefront of mathematical publishing. How did this happen and what does this mean for our future?

Springer Verlag has worked closely with the mathematical community for over a hundred years. In 1923 Ferdinand Springer rescued the two preeminent mathematical journals of the time, Mathematische Annalen and Mathematische Zeitschrift, when they were in deep financial trouble. This resulted in a letter of appreciation signed by Richard Courant, Albert Einstein, and David Hilbert, among others. This collaboration resumed, of course, after World War II, and Klaus was welcomed into the firm by Ferdinand Springer with the word "service." He described the scene in an unfinished memoir as follows:

One day my phone rang: "Springer here, please come to my office." Ferdinand Springer, the legendary publisher, did not usually deal with junior members of the staff nor had I been formally introduced to him. I went to his office unsure what this all meant. His personal secretary kindly advised that I should listen and quietly excuse myself when the "audience" was over. On entering his office I was greeted warmly as the new mathematics editor. Mathematics was one of Springer's favorite programs. He then proceeded to explain the raison d'être of a publisher: to facilitate the work of the authors by taking away the burdensome aspects of editing, producing, and most importantly distributing their work widely. He made it very clear that these added

Alice Peters is a publishing consultant and cofounder of the publishing company A $K$ Peters. Her email address is a1icepeters@gmai1.com.

David Mumford is professor emeritus of mathematics at Brown University and Harvard University. His email address is David_Mumford@brown.edu . 
values were the justification of a publisher's existence.

His fierce loyalty to authors and editors is confirmed by another story. When Ferdinand Springer sought to leave the occupied city of Berlin after World War II to rescue his family, he was stopped at a military control post. The commanding Russian officer demanded an explanation. Springer identified himself as a publisher of scientific books and journals (in his mind that was explanation enough) whereupon the officer commanded, "Tell me the names of the editors of such and such journal!" Springer had retained the names of Russian scientists and editors on the masthead of the journals they had served, despite the war. As he recited these names, the officer suddenly interrupted, "That's me, and I am honored to meet you." He provided Springer with free passage which allowed him to rejoin his family.

In 1971-72, Klaus formulated a plan to change the management of Springer from just the two active owners (Heinz Goetze and Konrad Springer) to a board of directors. He saw this as an important step in managing the growing company and as a necessary move for the future, as the owners were getting older. This plan was put in place with a board consisting of directors for editorial, production, marketing, and advertising (a bit of an anomaly, but that was an area that brought in a lot of money), each with equal votes. Klaus became the assistant to the editorial director and then later became the editorial director.

Some years later, a decision was made that the CFO should also become a director and that he would have the final say. Klaus very much disagreed with this decision and felt that it could alter his ideal that the purpose of the company should be serving science. He had many talks with Goetze about this and tried to convince him that there should be an editorial representative at the top (so to speak) on par with the financial director, and was always quite specific that it did not need to be him. When he was not able to sway Goetze's opinion, he told Goetze that he and Alice were going on vacation to France for one month, and if he did not hear from him otherwise, he would send in his letter of resignation on the last day of their vacation. Though he had just built a house in Heidelberg, had three children under the age of four and had "tenure" at Springer as a result of his joining the company from a university position, true to form he sent the letter of resignation. He was convinced that it would only be a matter of time until financial decisions outweighed editorial principles.
In fact, Klaus's beliefs were prophetic. Starting in 1999, Springer went through a succession of acquisitions. In 1999 the privately held publishing and mass media firm Bertelsmann acquired a majority share of Springer Verlag and formed the academic publishing firm BertelsmannSpringer. There were three subsequent acquisitions by private equity firms (in 2003, 2009, and 2013; the names of the firms are given in the Wikipedia entry for Springer Science+Business Media). In each case, the acquiring firm expected that Springer's return on capital could be increased under their management. For example, extending new distribution rights to scans enables a publisher to charge for online access to older articles that formerly generated no revenue. Early in the series of acquisitions, a group of six presidents of mathematical societies cooperated at the 2002 International Congress of Mathematicians on a proposal to the chief executive of BertelsmannSpringer to create a not-for-profit organization to take over the mathematics publishing part of the business. That was not to be. The private equity firms had a responsibility to place a priority on return on investment for their stakeholders, an incentive which often conflicts with the goal of publishing as a service, championed by Klaus,

Klaus understood this conflict of goals. In his own words [1]:

The economic model of a scientific/technical/ medical (STM) publisher plays a major role in its relationship with and impact on the scientific community. The major factors are pricing and distribution. Observing the publishing landscape from the point of view of the scientific community, one is struck by the enormous difference in pricing between journals and books at the large conglomerates and at the smaller houses. A closer look reveals that prices at large publishing houses are often higher by a factor of 2 or 3 . An even more detailed analysis shows that the higher pricing is directly related to smaller unit sales. The "chicken and egg" question comes to mind, and we believe that the answer lies in the economic model on which that publishing philosophy is based. Selling fewer copies at higher prices yields a higher profit margin, keeps warehousing costs down, and generally requires less marketing effort and expense; the larger house can rely on its core market-the libraries-all the while ignoring the matter of expanding marginal sales. If one thinks of a publisher as an entity with an obligation to publicize and, therefore, to maximize the distribution of the ideas contained in its publications, such 


\section{AMERICAN MATHEMATICAL SOCIETY MathSciNet Mathematical Reviews}

The premier gateway to scholarly literature in the mathematical sciences

Since 1940, Mathematical

Reviews (MR) has served

researchers and scholars in

the mathematical sciences by

providing timely information

on peer-reviewed articles

and books. The database of

more than 3 million items

contains reviews, abstracts,

and bibliographic information

for much of the world's

mathematical sciences

literature.

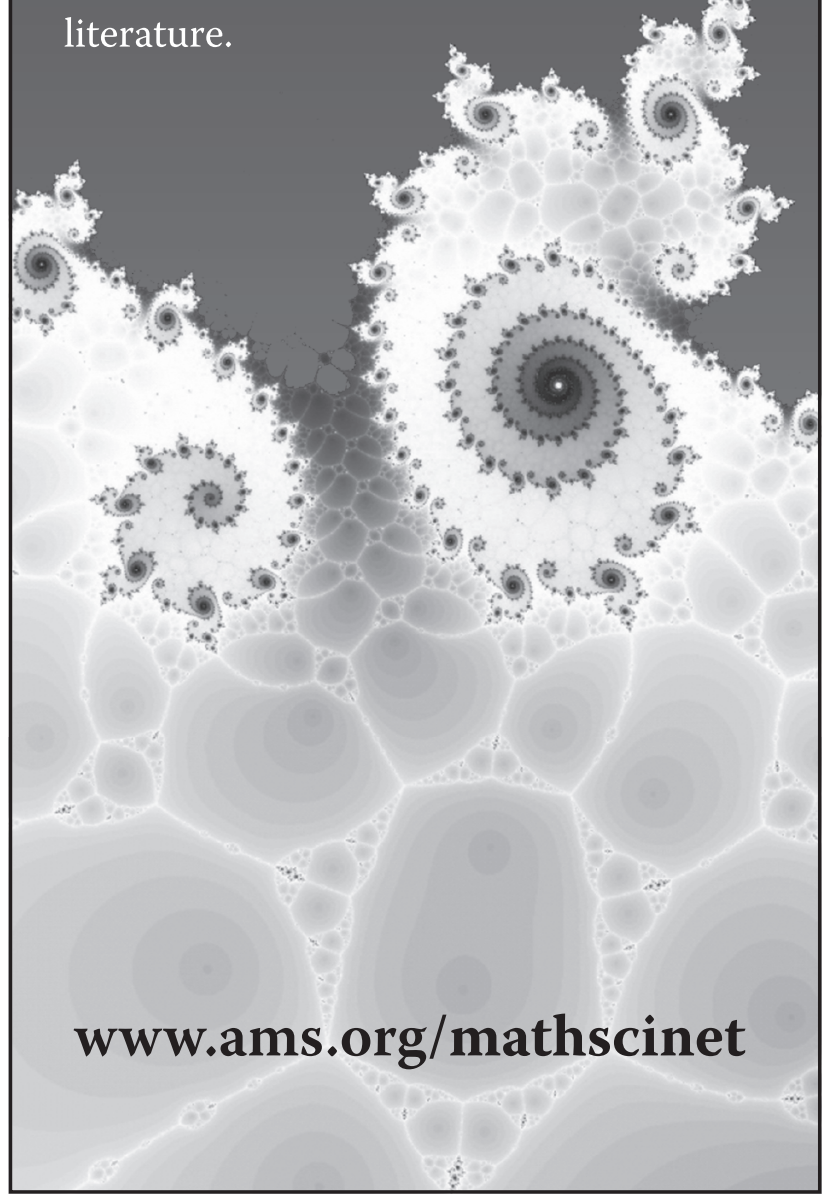

a publishing strategy certainly conflicts with the latter goal.

The idea of publishing as a service to the scientific community is something that was a core principle for Klaus throughout his life. In fact, just a few weeks before his death he wrote a short piece that he titled "A vanishing dream," articulating how essential this was to him-and to publishing in general.

Alice and I feel that we have lived a dream to preserve and provide a service that was once considered worthwhile. I mean "publishing as a service." Some time ago I came across the speech that Ferdinand Springer gave in 1952 after he had become a member of the Rotary Club in Heidelberg. That speech represents the raison d'être and professional ethics of publishing that I learned from Springer in a personal conversation and from Heinz Goetze in my early years at Springer Verlag.

That this concept (with few exceptions of small individual publishers) is widely lost is no secret but what bothers me intellectually is the fact that publishing companies can be run financially successfully without an intellectual mission and without thought to optimize sales (by numbers of copies) or to produce well-edited and designed books. They compensate these shortcomings by optimizing the bottom line through skimping on editorial and production costs and offsetting revenue loss from smaller per-title sales (by number) by inflating prices.

Mathematicians, by nature, want to concentrate on their work and resist worrying about the mechanics of communicating their results to their colleagues. But business models for publishing are changing rapidly in this digital age. Whether the new framework serves effectively the professional community or serves instead the financial firms that shift money from sector to sector following the scent of profit-this represents the major fork in the road that we are facing right now. Klaus's life and writings have a clear message: you need not be passive, and you can work to influence the outcome.

\section{References}

1. Klaus Peters, Why publish mathematics? Notices of the AMS, August 1999 